\title{
Research on Business Model of Large-scale Retail Enterprises under E-commerce Environment
}

\author{
Di Cao \\ Henan University of Animal Husbandry and Economy, Zhengzhou, Henan, 450044
}

Keywords: E-commerce; large-scale retail enterprise; economy effect

\begin{abstract}
This paper firstly analyzes the core documents of the business model, combs out the existing business model research, and constructs the conceptual framework of the business model. Then, on the basis of this framework, three large retail enterprises, Suning Appliance, Shanghai No. 1 Foods and Haishu Home, will be the case companies. Through the analysis of the content of the three business model elements, the relationship between elements and the design theme of the models, and comparison of the similarities and differences of their business models, the following conclusions of this paper can be drawn. The business model is a theoretical significance. Under the business environment, according to the proportion of online and offline business, it can be divided into online and offline combined mode, offline-based mode, and online-based mode. The resources and capabilities of the business model elements can be included in each other. The process of model value creation is to first present the value proposition to the customer, state the value of the customer, influence the resource capabilities of the retail business model, the composition and specific content of the value network and the profit model through the value proposition, and the value network and the resource capacity cooperate, then create value for customers, and at the same time profit model as a value acquisition mechanism, and ultimately create value for the enterprise itself. Value network fills the gap of enterprise resource capabilities. Customer value of retail business model comes from customer efficiency, customer benefit and customer experience in terms of transaction costs, and improves operational efficiency and operational effectiveness.
\end{abstract}

\section{Introduction}

The rise of e-commerce has impacted the retail industry while also providing opportunities for creating new value. The rise of e-commerce has led to changes in cross-border trading patterns within companies and across the value chain. New links have been created between customers, suppliers, and collaborators at the company's borders. The business model has become a tool for explaining the value creation of Internet companies in the new economy. Many entrepreneurs attract huge amounts of venture capital by virtue of their unique and innovative business models, such as the Amazon model, the Dell model, etc., which have been passed as successful business models. In addition, with the development of information technology, many traditional industries have begun to enter the ranks of e-commerce, from traditional industries to the interaction and integration of emerging industries. Business model research also extends from the Internet to traditional industries. Some companies are gradually disappearing under the new economy, while some companies are able to continue to grow. One of the important reasons is whether it can find its own business model in the new environment of e-commerce. Research on large-scale retail enterprises and their business models under the new environment has become a very urgent research issue.

\section{Business Model Conceptual Framework Construction}

Based on the results of the quantitative analysis of cross-sections, it was found that research on business models can be divided into four categories. Based on the research themes and theoretical basis of the clustering literature, these four categories are named: technical perspective, strategic perspective, organizational perspective, and innovative perspective. The first is the business model of technology. On the one hand, it is the study of early business models. It believes that the business 
model is the logistics connection point in the enterprise information system. It uses the business model to present the company's overall activities and provides the necessary information for leaders to make decisions. The other is the study of the e-commerce business model. E-commerce and information technology are closely related. The use of information technology can realize the connection between enterprises and enterprises, various departments within enterprises and between members, and complete process design and channel management to save manpower, material resources and financial resources, and improve the implementation of hardware and software. Efficiency, thus achieving value creation. Second, e-commerce companies have adopted different modes of operation than traditional enterprises, which have enabled them to obtain excellent revenues. The study of profit models has become an important part of the business model. Followed by the strategic perspective of the business model. The business model has become the source of the enterprise's competitive advantage. It needs to realize the value creation and value acquisition of the enterprise through resource integration and capacity enhancement. It is the enterprise's rent-seeking behavior [1]. Based on resource theory, competency, value chain (or value network), industrial organization theory and other strategic theories, the business model is explained as a source of competitive advantage. The idea that a novel and successful business model is an important resource endowment for a company. The ability to acquire, integrate and release resources is an essential ability for enterprises to survive and develop in a dynamic environment. Enterprise capabilities are an essential element of a successful business model. The deconstruction and restructuring of the value chain of enterprises and industries has become a necessary condition for the existence of a business model. Again, the business model of the organization's perspective focuses on the internal organization. And stressed the importance of the relationship between the members of the organization and the corporate culture in the business model. It is believed that the business model is composed of organizational activities and organizational unit relationships. The composition of organizational units and relationship management are important ways for successful business models. In addition, the academic community makes a distinction between business models and processes. The business model is an intermediary that links enterprise strategies and processes, and it has an intersection with both. The process is more specific than the business model, and it is more biased toward implementation. Finally, the business model of innovation perspective. It can be summarized as two aspects: the business model as an innovative tool and the business model as the main body of innovation. Specifically, it is divided into the following three points. The first is based on the technology diffusion theory, using the business model as an innovative tool to realize the commercialization of technological innovation. The second is the strategic network. The embeddedness of the network enhances the customer's buying behavior, realizes the value creation of the customer, and provides a theoretical basis for explaining the value acquisition of the enterprise. The third is open innovation, which solves the problem of the enterprise's access to value in the case of multiple participants. The business model of innovation perspective focuses on traditional industries, non-profit sectors and non-profit organizations [2].

Comprehensive analysis, the quantitative analysis results of a single cross-section confirmed that the business model can be divided into four categories: e-commerce, strategy, organization, and innovation, and clearly presented four types of research focus and representative publications. Research in the field of e-commerce consists of two areas: technology and management. Research in the strategic area focuses on the competitiveness of the enterprise. Organizational areas include the organizational structure and performance. Innovation research is divided from technology diffusion and business model innovation. Expand. At the same time, there are many similar features in these four areas. Harvard Business Review promotes the common development of business models in different fields, and case studies have become the main method of research on business models. Researchers start from the fields of technology, strategy, organization, and innovation and use related theories to explain or measure business models and business model innovations. These research branches are cross-convergence and jointly support the development of the business model field, prompting it to gradually become a new independent cross discipline.

After analyzing the vertical and horizontal direction of business model research, this paper finds 
that business models, after experiencing the initial stage, e-commerce stage, questioning stage, strategic and organizational application stage, and innovative application stage, tend to parallel different branches of technology, strategy, organization, and innovation. The large-scale development phase of non-capture and cross-convergence is forming a new independent cross discipline. Business model constructs from the initial computer terminology to the e-commerce profit model description, to be challenged, and then to the theoretical foundation. Many scholars are calling for the establishment of a unified conceptual framework for business models because the lack of a unified understanding of the business model is the root cause for questioning and the primary obstacle to the continued development of the field (eg, to build a unified business model concept. The framework first needs to integrate the research results in the four areas of technology, strategy, organization and innovation [3]. Only if these four major areas are covered can we clarify the overall understanding and research results of the current research on the business model, and the business model must be structured. Embodying value creation and value acquisition, whether in the field of technology, strategy, organization, or innovation, is centered on the value creation and value acquisition activities of the company, which are the links that connect research results in different fields. Value acquisition is the core logic of the emergence of business model constructs from development to development.In order to explain the cross-subsidy phenomenon of the Internet, business models are introduced into the field of management.The emergence of business models is to describe, explain, analyze and guide the value creation activities of enterprises. And value acquisition activities. Finally, as described above As mentioned in the stage analysis business model component, the business model is composed of internal elements of the company and cross-enterprise boundary elements (such as value network, value proposition, and the research in the organization field focuses on the value creation within the enterprise. In the value-acquisition process, the resource endowments possessed by the company have become excellent values, while the research in the strategic and technical fields focuses on the cross-border transactions of enterprises, and the elements of the enterprise boundary have become the focus of attention of researchers in these fields. The relationship network with partners and the value commitment to customers have become the source of the value created by the enterprise, while the innovation field is more concerned with the creation and acquisition of new values for the innovation of the element content and the element combination relationship.

\section{Case Analysis of Large-scale Retail Enterprises in E-commerce Environment}

In the process of semi-structured interviews, the research team members asked the respondents to elaborate as much as possible the content of the constituent elements of the business model of the retail company under their current e-commerce environment, including the company's value proposition, value network, The core themes surrounding the design of resource capabilities, profitability models, and business models. At the same time, ask the company how to locate the target market, how its product categories and related services meet customer needs, how to cooperate with suppliers and other partners, how resources and capabilities create value for their target customers, and how to carry out cost design and control. How business model elements combine to achieve customer value [4]. The following is a detailed elaboration of the elements, elements, and design topics of the Suning Appliance business model under the e-commerce environment. In the e-commerce environment, Suning put forward the value proposition of "full category, all-round, full-customer". In the process of transitioning from a traditional home appliance chain to a "cloud merchant" that integrates online and offline platforms, its target customers have shifted from traditional male customers in traditional stores to all customer groups. In order to meet the needs of different customer groups at different angles and in different aspects, Suning Electric fully explores the depth and breadth of e-commerce, not only selling traditional household appliances and electrical appliances, but also expanding product categories as much as possible, selling maternity and baby supplies, books, and air tickets. Millions of product categories, such as daily merchandise, and data services. One is the supplier. Suning Appliances and suppliers support each other and there is competition between them. On the one hand, suppliers support Suning 
Appliances in terms of price and marketing. For example, some well-connected suppliers will give price concessions. When suppliers advertise their activities, Suning Appliances are mentioned in the purchasing channels and publicity media. Direct consumers to Suning Appliance to purchase. On the other hand, Suning Appliance provides supplier support for product promotion and consumer data. As a retail company directly facing the final consumer, whether online or offline, Suning Electronics has sales data for each brand and each model. Through the data processing of the R\&D department, it is possible to provide accurate and effective consumer market-oriented guidance for its suppliers with better relationships [5].

The second is the brand business. Suning Electric built its own e-commerce platform and opened its platform to brand owners. After the brand application is online, the company will be able to conduct shop operations and product online at Suning Appliance. The two are mutual supportive relationships. Suning Appliance provides brand companies with a free platform, free of annual fees and guarantee deposits. And provide free delivery service for the brand business to complete the "last mile" delivery service. At present, Vanke Eslite and Lefeng two professional e-commerce companies have officially settled in Suning Appliance. On the other hand, the entry of brand owners has provided support for Suning Appliance to expand product categories, fully meet customer needs, and attract customers. Some products that Suning Appliance cannot specialize in, such as clothing, daily necessities, etc., are completed by brand owners and achieve a win-win situation for both parties. The third is shopping website. Suning Appliance acquired the domestic professional mother-to-child website "Red Kid" and the "renewal" of the beauty website. Before the rise of e-commerce, "Red Kids" has been engaged in telephone sales and catalog sales. The 2008 e-commerce is known as China's mother and baby flagship website. When you access via the original "Red Kid" "renewal subscription" website, you will directly jump to the homepage of Suning Appliance, and Suning Appliance will use it as an option in the home page. Click here to enter. Second, Red Kids and Suning Appliance share Suning Appliance's easy-to-purchase warehouse logistics system, supply chain management system, and membership management system to realize the integration of resources of both parties [6].

The resource capabilities of the business model components are the resources and capabilities needed to deliver the promised customer value to the target customer. Through the analysis of interviews and related secondary data, Suning Appliance's resource capabilities mainly include: physical stores, its own network platform, logistics and distribution, organizational structure, brand reputation, talent management, and supply chain management. Fourth, supply chain management system and related experience. The research and development of Suning Appliance is mainly concentrated in the Beijing R\&D Center, focusing on the research and development of technical framework and information system. The R\&D center establishes an internal information system through cooperation with other related technology companies and realizes information communication among various regions and departments. And create a supplier platform to include suppliers and complete the exchange of information with them. Based on a well-established information management system, Suning Appliance can achieve timely and accurate information exchange and can handle regular incidents in a timely manner, and sudden incidents can be properly responded to. Fifth, the brand reputation. 2003 brand value of the device has risen to 95.6 billion, the world's laboratories will be included in China's most valuable 500 brands. Suning Appliance has become one of the well-known brands in China, and its brand reputation has become the core resource of traditional store retailing to online and offline integration models. Its brand awareness has spread all over the country. Everyone knows Suning Appliance. Its brand influence created online is directly transmitted online. Sixth, the organizational structure. Suning Electronics joined e-commerce sales activities in traditional retail sales activities. In order to achieve online and offline integration, Suning Appliance changed its name from Suning Appliance to Suning Appliance, weakening the image of traditional electrical appliance sellers and emphasizing traditional retail and e-commerce. Integration. Suning Appliance made organizational changes at the same time as it was renamed, joined the e-commerce operations headquarters, and was in a position affiliated with the operating headquarters of the chain platform. Accordingly, the regional organization structure also 
joined the e-commerce center or ministry [7]. Suning Appliance supports the synchronization of online and offline business in the organizational structure design, and gets rid of the initial online and offline segmentation business, but will integrate the two, unified procurement, unified management and unified promotion.

First of all, the cloud merchant model creates superior customer value around the advantages of combining online and offline. Its value proposition emphasizes "all", providing as many product categories as possible to meet the needs in all directions and serving as many customers as possible. Suning Appliance focuses on its own physical stores, online shopping platform and many years of retail experience, online and offline cooperation (such as online and offline with the same price, online offline order picking and customer service), and the construction of a nationwide storage center and logistics Delivery system, delivering the "last mile" delivery service. The lack of resource capacity is supported by the resource capabilities owned by the value network members. Suning Appliance, through cooperation, acquisitions, strategic alliances, and value network members jointly enrich product categories and maintain an online shopping platform.

Second, the cloud business model achieves effective transaction cost control while creating as much transaction value as possible. The central location in the value network determines that Suning Appliance can influence other network members, have pricing power for most of the products sold, and obtain more value by depressing prices from suppliers. In addition, the complementarity of the logistics distribution system, the length of the inventory period, and the degree of utilization of resource capabilities all affect the transaction costs of Suning Appliance.

Finally, the design of the cloud-business model expands the creation of customer value on the basis of ensuring a reasonable cost, and achieves the balance between efficiency and efficiency. The creation of its transaction value mainly through the creation of product value and service value for customers, and the level of transaction value is reflected in the customer benefit, customer efficiency and customer experience level. The reduction of transaction costs is reflected in the improvement of operational efficiency and operational efficiency. On the one hand, the improvement of operational efficiency and efficiency is cost control. On the one hand, it is to increase the use of resource capabilities and value networks, and create more products and service values for customers.

\section{Cross-case Analysis of Large-scale Retail Enterprises in E-commerce Environment}

In the e-commerce environment, the focus of online and offline business models of the three case companies is not the same. The Suning Appliance model regards shop and e-commerce as two equally important aspects. The focus of the model is the synergy and cooperation between online and offline. The depth and breadth of e-commerce allows Suning Appliance to serve all customers by creating product categories, online and offline prices, online ordering and store self-collection services to create value for customers while closing down some of the invalid or Inefficient stores, relatively reduced traditional businesses to improve operational efficiency. However, under the influence of e-commerce, Shanghai No. 1 Food Co., Ltd. still insists on traditional stores as its focus, and only sells a small portion of self-operated products online. It is committed to expanding traditional stores and developing store business. The business model of Haicang House is only to increase the network platform. Suppliers are the main members of all retail enterprise value networks. While supplying products for retail companies, other roles are relatively different depending on the business model of the company. Suning Appliance's suppliers share part of their logistics, and Hailan Home's suppliers share the inventory risk. Second, the composition of other network members is also relatively different. Value network is the way to get the resources of an enterprise. In the retail industry, in order to realize value creation, it is necessary to assign part of the resource capabilities to the members of the value network and acquire the resource capabilities that they lack through cooperation, strategic alliances, or acquisitions. Finally, in the value network of large-scale retail enterprises, large-scale retail enterprises are at the center of the value network and have control or significant influence on other network members. Therefore, network management of value networks has become an important content of value networks for large-scale 
retail enterprises [8].

The major costs of large-scale retail enterprises include inventory, rental, promotion, personnel, logistics, and the development, maintenance, or use of network platforms. The three case companies have undertaken the site selection, decoration, promotion of stores and/or network platforms, and unified purchasing and unified inventory on-line and off-line. From product procurement to product sales, to distribution and after-sales service are all under the control of retail companies. Second, the income of the three case companies comes from both customers and members of the value network. Its main goal is to increase the appeal of the entire store and/or the entire network platform to suppliers and consumers. The formulation of value propositions, the composition of resource capabilities, and the construction of value networks are all about creating customer value. For customers to create products and service value, and create a good customer experience, more customers are willing to go to the retailer to buy products, to earn revenues while selling products, and to receive lower prices from suppliers, brand owners, etc. Price products and higher entry fees, revenue sharing, etc.

The resource advantages of Suning Appliance are entity store, retail experience and full-category network platform. Its revenue mainly comes from online and offline product sales revenue. The online platform has just started to go online and has not yet formed its resource advantage. The online platform usage fee cannot be used as one of its major sources of income for more sophisticated e-commerce (such as Taobao and Jingdong Mall). Its extensive retail experience is integrated online and offline, and online ordering and offline pick-ups work in tandem with each other, enabling offline helplines to increase online sales revenue. The resource advantages of Shanghai No. 1 Food are represented by the operating area, location and long-term food retail experience of the physical stores. Sales revenue of self-operated products has become its main source of income. At the same time, large-scale stores occupy rental income in their sources of income. Larger proportions. The resources advantage of Haicang House is the brand influence and the unified management ability of stores, so brand promotion has become its main purpose. At the same time, influential brands have attracted franchisees to join, and franchisees have been responsible for the operating costs of their stores, which has reduced the proportion of store expenses in Haishu's home cost structure. The last is influenced by the value network. The main members of the Suning Appliance Value Network are suppliers and technology partners. All of its sales products come from suppliers, and inventory is its most important cost. And other technology partners to build and maintain their own network platform, the construction and promotion of network platform is its main cost. The main members of Shanghai No. 1 Foods' Value Network are superior groups, brand owners and suppliers. The costs are mainly inventory and rent. The special relationship with superior groups and the long-term friendly cooperation with Wanda and other real estate developers make Shanghai No. 1 Food Co., Ltd. To the area of tens of thousands of square meters and the rent is lower than the market price. The value network of Haicang House is mainly franchisees and suppliers. The cost is mainly related to brand promotion. In addition to the product sales, the income also uses the franchise fee collected for the investment and the related benefits obtained. The three case companies are central to their value network and have pricing power for the products supplied by suppliers. When retailers obtain products from suppliers at a lower price, their income is relatively higher. Moreover, the central position of the network is conducive to retailers charging their franchisees for additional fees such as initial fee, and can provide longer payment terms to suppliers, thus reducing the operating costs of retailers.

In the e-commerce environment, the value proposition of retail companies tends to be both online and offline, which requires the retail business model to conduct business online. For retail companies that do not have their own websites, they will need to join other e-commerce platforms and need to include the e-commerce platform in their value network. Value propositions affect the membership of value networks and the role of members. "All" advocated Suning Appliance to expand product categories and achieve all-round, and its value network is to increase the occupancy of brand owners as much as possible, acquire other shopping websites, and work closely with technology partners. Shanghai No. 1 Foods emphasizes "safety" and acquires the quality and 
efficiency of food product manufacturers' control of product production. The "characteristic" value proposition requires that the first food diversified brands and affiliates stay. The efficiency of Haicang House advocates that its suppliers and franchisees play an important role in its value network.

\section{Conclusion}

Based on text analysis, this paper constructs a unified business model conceptual framework. Summing up the research results of the four major business models of strategy, organization, innovation, and technology, building the conceptual framework of the business model from the three dimensions of core logic, element composition, and design theme, demonstrates the necessity and importance of the existence of business model constructs. Sex. It helps to solve the problem of unclear understanding of the business model, questions the business model and other issues, and provides some inspiration for the development of the business model theory.

\section{Acknowledgements}

Henan University of Animal Husbandry, Business Administration Key Business Discipline Construction Project (MXK 2016201)

Henan University of Animal Husbandry, Business Circulation Enterprise Development and Business Model Innovation Research Team (2016-5)

\section{References}

[1] Wang Xuedong, Dong Dahai. Review of foreign business model expression model and construction of integrated expression model [J]. Foreign Economics and Management. 2013 (04)

[2] Jing Linbo. Technological change and the development of e-commerce in China [J]. Price Theory and Practice. 2013 (03)

[3] Song Qian, Wang Neng. Business Model Innovation of Domestic Retail Enterprises under Internet Conditions [J]. E-commerce. 2013 (03)

[4] Mei Yu. Element Analysis of Business Models: Taking Suning Appliance as an Example [J]. Business Manager. 2013 (02)

[5] Jia Danyang. On the Similarities and Differences of Financial Accounting Statements and Statistical Financial Statements [J]. Friends of Accounting. 2012 (13)

[6] Wang Xuedong, Dong Dahai. Research on the Subject Attribute and Orientation of Business Models and Future Research Prospects [J]. Foreign Economics and Management. 2012 (03)

[7] Wang Guoshun, Gold. The profit model and value chain optimization of retail enterprises [J]. Journal of Beijing Technology and Business University (Social Sciences Edition). 2012 (02)

[8] Zhang Xia, Mao Jiye. Progress Review and Improvement Steps of the Case Study of Domestic Enterprise Management: An Overview of China Enterprise Management Case and Theory Construction Research Forum (2011) [J]. Management World. 2012 (02) 